\title{
Bridging the Gap between Perceptual and Cognitive Perspectives on Absolute Pitch
}

\author{
Stefan Elmer, ${ }^{1 \star}$ Lars Rogenmoser, ${ }^{1 \star}$ Jürg Kühnis, ${ }^{1}$ and ${ }^{\oplus}$ Lutz Jäncke ${ }^{1,2,3,4,5}$ \\ ${ }^{1}$ Division Neuropsychology, Institute of Psychology, ${ }^{2}$ Center for Integrative Human Physiology (ZIHP), ${ }^{3}$ International Normal Aging and Plasticity Imaging \\ Center (INAPIC), and 4University Research Priority Program (URPP) "Dynamic of Healthy Aging," University of Zurich, CH-8050 Zurich, Switzerland and \\ ${ }^{5}$ Department of Special Education, King Abdulaziz University, 21589 Jeddah, Saudi Arabia
}

\begin{abstract}
Absolute pitch (AP) refers to the rare ability to identify the chroma of a tone or to produce a specific pitch without reference to keyality (e.g., G or C). Previously, AP has been proposed to rely on the distinctive functional-anatomical architecture of the left auditory-related cortex (ARC), this specific trait possibly enabling an optimized early "categorical perception". In contrast, currently prevailing models of AP postulate that cognitive rather than perceptual processes, namely "pitch labeling" mechanisms, more likely constitute the bearing skeleton of AP. This associative memory component has previously been proposed to be dependent, among other mechanisms, on the recruitment of the left dorsolateral prefrontal cortex (DLPFC) as well as on the integrity of the left arcuate fasciculus, a fiber bundle linking the posterior supratemporal plane with the DLPFC. Here, we attempted to integrate these two apparently conflicting perspectives on AP, namely early "categorical perception" and "pitch labeling". We used electroencephalography and evaluated resting-state intracranial functional connectivity between the left ARC and DLPFC in a sample of musicians with and without AP. Results demonstrate significantly increased left-hemispheric theta phase synchronization in AP compared with non-AP musicians. Within the AP group, this specific electrophysiological marker was predictive of absolute-hearing behavior and explained $\sim 30 \%$ of variance. Thus, we propose that in AP subjects the tonal inputs and the corresponding mnemonic representations are tightly coupled in such a manner that the distinctive electrophysiological signature of AP can saliently be detected in only 3 min of resting-state measurements.
\end{abstract}

Key words: absolute pitch; associative memory; intracerebral functional connectivity; pitch labeling; resting-state EEG; theta phase synchronization

\section{Introduction}

The ability to identify a note without relying on a reference tone (Takeuchi and Hulse, 1993; Zatorre, 2003; Levitin and Rogers, 2005) has an incidence of $<1 \%$ (Takeuchi and Hulse, 1993), whereas Asian people speaking tonal languages have a higher rate (Deutsch et al., 2006, 2009). Absolute pitch (AP) is supposed to originate from an intertwining of genetic factors (Baharloo et al., 1998; Gregersen et al., 1999), early exposure to music (Gregersen et al., 2001; Deutsch et al., 2006; Meyer et al., 2011), and intensity of musical training (Gregersen et al., 2001; Elmer et al., 2013).

Until now, there is functional evidence indicating that AP is somehow related to an optimized early "categorical perception" (Siegel, 1974) at the processing level of the auditory-related cortex (ARC; Hirata et al., 1999; Ohnishi et al., 2001; Itoh et al., 2005;

\footnotetext{
Received July 22, 2014; revised 0ct. 20, 2014; accepted 0ct. 21, 2014.

Author contributions:S.E., L.R., J.K., and L.J. designed research; L.R. performed research; J.K. contributed unpublished reagents/analytic tools; S.E. analyzed data; S.E., L.R., J.K., and L.J. wrote the paper.

This research was supported by the Swiss National Foundation (grants 320030-120661, 4-62341-05, and 320030B_138668/1 to L.J.).

*S.E. and L.R. contributed equally to this work.

The authors declare no competing financial interests.

Correspondence should be addressed to either Dr. Stefan Elmer or Prof. Dr. Lutz Jäncke, Institute of Psychology,

Division Neuropsychology, University of Zurich, Binzmühlestrasse 14/25, CH-8050 Zurich, Switzerland, E-mail: s.elmer@psychologie.uzh.ch or lutz.jaencke@uzh.ch.

DOI:10.1523/JNEUROSCI.3009-14.2015

Copyright $\odot 2015$ the authors $\quad 0270-6474 / 15 / 350366-06 \$ 15.00 / 0$
}

Wu et al., 2008; Schulze et al., 2009; Meyer et al., 2011; Matsuda et al., 2013). This perspective is strengthened by previous anatomical work suggesting a relationship between the surface area of the left planum temporale (PT; Schlaug et al., 1995; Keenan et al., 2001; Luders et al., 2004; Bermudez et al., 2009), or PT asymmetry (Keenan et al., 2001), and the ability to perceive tones absolutely. However, such a relationship has been called into question due to methodological limitations, including studies that not adequately matched for age of commencement of musical training or training intensity (Itoh et al., 2005; Kamiyama et al., 2010), performed measurements in a noisy MRI environment (Ohnishi et al., 2001; Schulze et al., 2009; Oechslin et al., 2010), or compared AP musicians with non-musicians (Hirata et al., 1999; Meyer et al., 2011).

Prevailing two-component models (Zatorre and Beckett, 1989; Zatorre, 2003; Levitin and Rogers, 2005) suggest that AP is constituted by one perceptual (i.e., "categorical perception") and two cognitive ["pitch memory" (i.e., explicit memory) and "pitch labeling" (i.e., implicit associative memory)] mechanisms, whereby the latter probably more likely constitutes the bearing skeleton of AP. However, since "pitch memory" is common to almost all individuals when recalling popular songs from memory (Halpern, 1989; Levitin, 1994), the mnemonic association between pitches and labels (i.e., "pitch labeling") has been proposed to constitute the most distinctive trait of AP (Elmer 


\section{ROIs: dorsolateral prefrontal cortex}

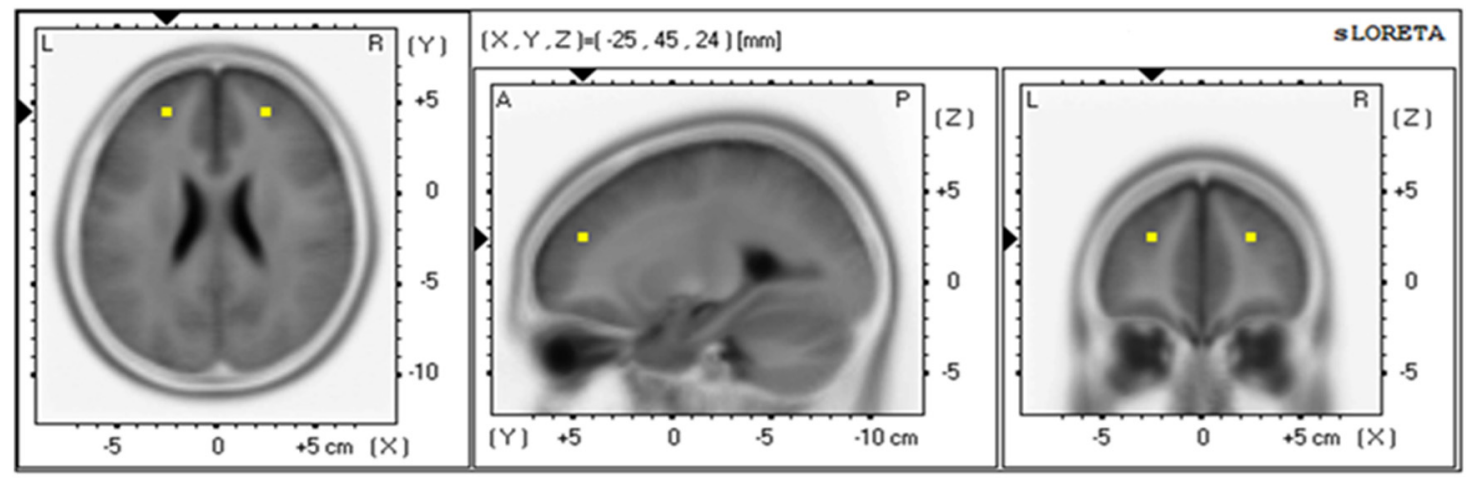

ROIs auditory-related cortex

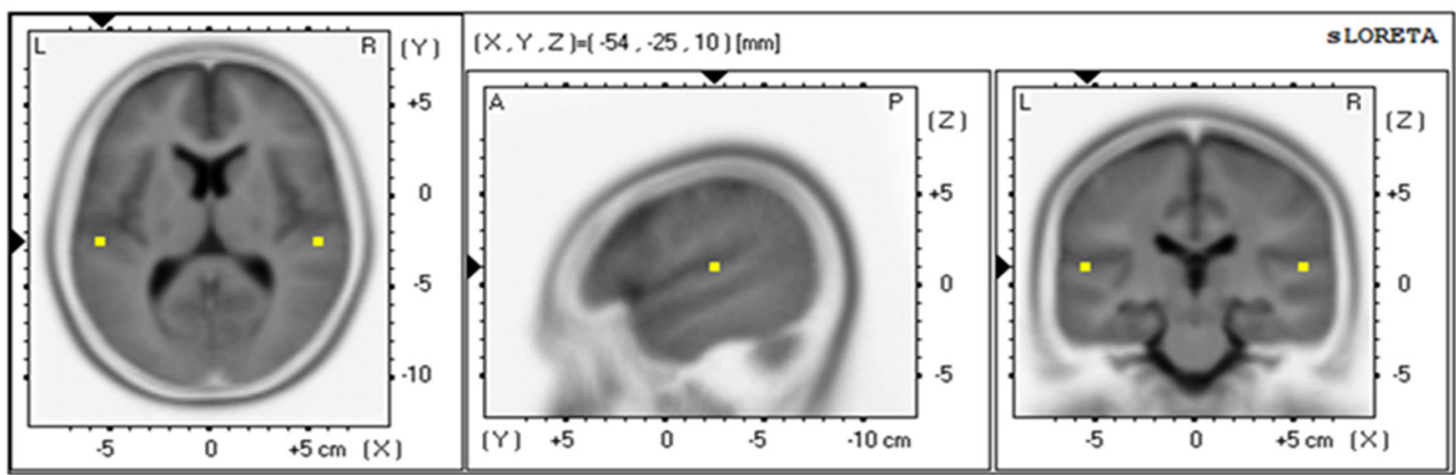

Figure 1. ROIs position within the 3D MNI space. Left, Transversal view; middle, sagittal view; and right, coronal view. Top, DLPFC and bottom, ARC.

et al., 2013; Rogenmoser et al., 2014). This associative memory component is assumed to rely, among other mechanisms, on the recruitment of the left dorsolateral prefrontal cortex (DLPFC; Zatorre et al., 1998, 2003; Ohnishi et al., 2001; Bermudez and Zatorre, 2005; Bermudez et al., 2009) as well as on the integrity of the arcuate fasciculus (AF; Oechslin et al., 2009; Loui et al., 2011; Jäncke et al., 2012), a fiber bundle linking the posterior supratemporal plane with the DLPFC (Makris et al., 2005).

Neuronal oscillations in the theta frequency range $(\sim 4-7 \mathrm{~Hz})$ seem to be more closely linked to mnemonic functions than they are to other cognitive processes (Ward, 2003). In addition, theta oscillations have previously been identified as a salient marker of associative memory functions (Ward, 2003; Crespo-Garcia et al., 2012; Chen et al., 2013). Therefore, we examined the possibility to integrate early "categorical perception" and "pitch labeling" mechanisms by evaluating intracranial resting-state connectivity in the theta frequency range between the left ARC and DLPFC (Fig. 1).

\section{Materials and Methods}

Participants. All professional AP (total 16, 4 men, mean age $=25.4$ years, $\mathrm{SD}=9.6$ years) and non-AP (NAP) musicians (total 10,2 men, mean age $=24.4, \mathrm{SD}=3.0$ years $)$ measured in the present study were consistently right-handed, as revealed by the Annett Handedness Inventory (Annett, 1970). None of the participants reported a history of neurological, psychiatric, or audiological disorders. All subjects denied consumption of illegal drugs or regular medication and pure tone audiometry (Home Audiometer software; http://www.esseraudio.com/de/homeaudiometer-hoertest.html) revealed an unremarkable audiological status. The subjects were paid for participation, the local ethics committee approved the study, and written informed consent was obtained from all participants.

History of musical training. History of musical training was assessed by using an in-house questionnaire (Elmer et al., 2012, 2013). Based on this questionnaire, we evaluated the age of commencement of musical training, the instruments played, as well as the estimated cumulative number of training hours across life span.

Musical aptitudes. Musical aptitudes were quantified by using the "Advanced Measure of Music Audition” (AMMA; Gordon, 1989). During the AMMA test, the volunteers had to listen to short pairs of piano sequences and to decide whether the sequences were equivalent, rhythmically different, or tonally different.

Absolute pitch ability. AP ability was evaluated by a pitch labeling test previously used by our group (Oechslin et al., 2009). Subjects listened to 108 pure sine wave tones presented in a pseudorandomized order and were instructed to write down the tonal label immediately after hearing the accordant tone. The tones ranged from A3 (tuning: A4 $=440 \mathrm{~Hz}$ ) to A5 and were presented three times each, whereby the same tones were never presented successively. Each tone presented during the test had a duration of $1 \mathrm{~s}$. The interstimulus interval was $4 \mathrm{~s}$ and filled with Brownian noise. The accuracy was evaluated by counting the total number of correct responses. Semitone errors were counted as incorrect responses to increase discriminatory power.

Cognitive capability. Between-group differences in intelligence were evaluated by applying a short German intelligence test (MehrfachwahlWortschatz Intelligenz Test, MWT-B). This procedure permits the estimation of crystalline intelligence in a short time, and has previously been shown to correlate fairly well $(r=0.72)$ with the global intelligence quotient in healthy adults (Lehrl and Fischer, 1992). The MWT-B consists of 37 items ordered as a function of difficulty level. For each item, the subjects had to choose the unique word with a meaning out of five pseudowords. 
EEG data acquisition and preprocessing. During resting-state measurements the subjects were instructed to remain relaxed in a passive status with closed eyes and to not explicitly force any kinds of thoughts. Continuous resting-state EEG ( 32 electrodes +2 eye channels, provided by Easy Cap) was recorded during an eyes-closed period of 3 min with a sampling rate of $1000 \mathrm{~Hz}$ and a high-pass filter of $0.1 \mathrm{~Hz}$ by using an EEG amplifier (Brain Products). The electrodes (sintered silver/silver chloride) were located at frontal, temporal, parietal, and occipital scalp sites according to the international 10-10 system (Fp1, Fp2, F7, F3, Fz, F4, F8, FT7, FC3, FCz, FC4, FT8, T7, C3, Cz, C4, T8, TP9, TP7, CP3, CPz, CP4, TP8, TP10, P7, P3, Pz, P4, P8, O1, Oz, and O2). The reference electrode was placed on the tip of the nose, and electrode impedance was reduced to $<10 \mathrm{k} \Omega$ by using Electro-Gel conductant. For all preprocessing steps, we used the Brain Vision Analyzer software package (version 2.01; Brain Products). Data were filtered off-line from 1 to $20 \mathrm{~Hz}$, and artifacts (i.e., eye movements and blinks) were eliminated by using an independent component analysis (Jung et al., 2000) in association with a semiautomatic raw data inspection. After data preprocessing, the resting-state period was segmented into single sweeps of $2000 \mathrm{~ms}$, and data were subjected to intracranial functional connectivity analyses by using the eLORETA toolbox.

Intracranial functional connectivity analyses. Functional connectivity was evaluated by using intracranial lagged phase-synchronization values and the eLORETA software package (http://www.uzh.ch/keyinst/loreta. $\mathrm{htm}$ ). Lagged phase synchronization is a measure for the similarity (a corrected phase synchrony value) between signals in the frequency domain based on normalized (umodule) Fourier transforms; thus it is related to nonlinear functional connectivity. This lagged connectivity measure is accurately corrected as it represents the connectivity between two signals after the instantaneous zero-lag contribution has been excluded (Nolte et al., 2004; Stam and van Straaten, 2012). Such a correction is necessary when using scalp EEG signals or estimated intracranial signals (EEG tomography), because zero-lag connectivity in a given frequency band is often due to nonphysiological effects or intrinsic physics artifacts, in particular volume conduction and low spatial resolution, which usually affect other connectivity indices. Thus, this measure is thought to contain only true physiological connectivity information.

In the current implementation of eLORETA, computations were made within a realistic head model (Fuchs et al., 2002), using the Montreal Neurological Institute (MNI) 152 template (Mazziotta et al., 2001), with the 3D solution space restricted to cortical gray matter, as determined by the probabilistic Talairach atlas (Lancaster et al., 2000). The intracranial volume is partitioned in 6239 voxels at $5 \mathrm{~mm}$ spatial resolution. eLORETA images represent the electric activity at each voxel in the neuroanatomic MNI space as the exact magnitude of the estimated current density. Anatomical labels and Brodmann areas (BA) are reported using MNI space, with correction to Talairach space (Brett et al., 2002).

For intracranial functional connectivity analyses, we selected two a priori defined regions of interest (ROI) in each hemisphere (Fig. 1). These two ROIs consisted of BA 41/42 (ROI 1, ARC) and BA 9/10/46 (ROI 2, DLPFC) that were specifically selected based on previous literature on AP (Schlaug et al., 1995; Keenan et al., 2001; Ohnishi et al., 2001; Luders et al., 2004; Bermudez and Zatorre, 2005, 2009; Bermudez et al., 2009). Intracranial connectivity between the two left-sided ROIs was evaluated based on a specific a priori hypothesis. In addition, since previous literature reported right hemispheric effects along the supratemporal plane (Schulze et al., 2009; Jäncke et al., 2012; Wengenroth et al., 2014) and the DLPFC in AP musicians (Bermudez et al., 2009, Zatorre et al., 1998; Schulze et al., 2009), we also investigated right-sided connectivity between ROI 1 and 2. For functional connectivity analyses between the two ROIs, a method using a single voxel at the centroid of the BAs was chosen. Details on eLORETA connectivity algorithms can be found in previous reports by Pascual-Marqui et al. (2011). For each group, eLORETA functional connectivity was computed in a specific a priori selected frequency band previously shown to reliably reflect mnemonic processes and information integration (Ward, 2003), namely theta (4-7 Hz).

Statistical analyses. Intracranial connectivity data were subjected to outlier statistic, and one subject per group ( $>2 \mathrm{SD})$ was excluded from

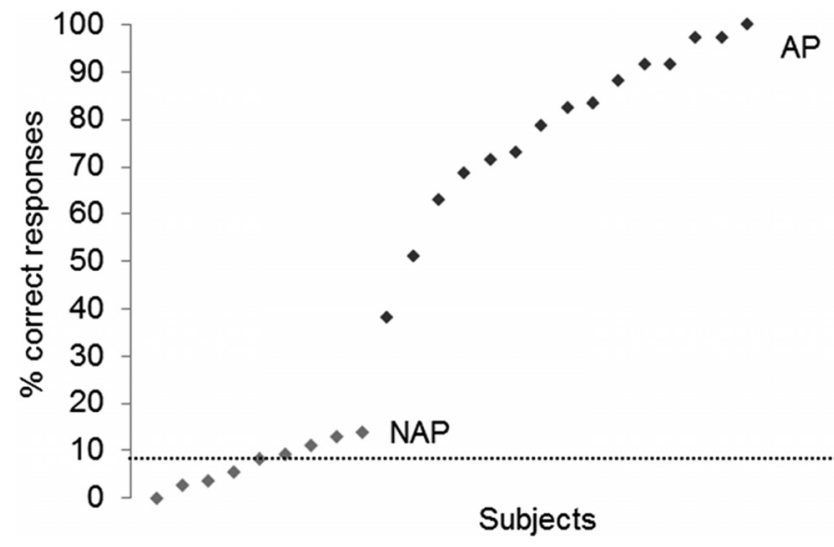

Figure 2. Distribution of pitch-labeling performance. Black diamonds, AP musicians ( $N=$ 15); gray diamonds, NAP musicians $(N=9)$. The dashed line depicts chance level $(8.3 \%)$.

data analyses. After having tested for normal data distribution by using the Kolmogorov-Smirnov test, connectivity data were subjected to a $2 \times$ 2 ANOVA (two groups and two hemispheres). Interaction effects were further inspected by using $t$ tests (corrected for multiple comparisons by using the Bonferroni procedure). Correlative analyses were performed by using partial correlations corrected for the influence of age of commencement of musical training (Gregersen et al., 2001; Deutsch et al., 2006; Meyer et al., 2011; Elmer et al., 2013).

\section{Results}

\section{Autobiographical and behavioral data}

The two groups did not significantly differ in age $\left(t_{(22)}=0.471\right.$, $p=0.642$, two-tailed $)$, cognitive capability $\left(t_{(22)}=-0.165, p=\right.$ 0.871 , two-tailed), age of commencement of musical training $\left(t_{(22)}=-1.7, p=0.103\right.$, two-tailed $)$, cumulative number of training hours across life $\operatorname{span}\left(t_{(22)}=1.537, p=0.139\right.$, twotailed), nor in musical aptitudes (group, $F_{(1,22)}=0.013, p=$ 0.909 ; group $\times$ tonal $/$ rhythmical, $F_{(1,22)}=1.332, p=0.261$; tonal/rhythmical $F_{(1,22)}=8.807, p=0.007$, mean tonal $=33.16$, mean rhythmical $=34.25)$. However, as expected, the AP group performed significantly better on the pitch-labeling test $\left(t_{(22)}=\right.$ $14.514, p=4.63^{\star} 10^{-11}$, two-tailed; Fig. 2).

\section{Intracranial functional connectivity}

The $2 \times 2$ ANOVA revealed a significant interaction effect between group and hemisphere $\left(F_{(1,22)}=5.383, p=0.030\right)$. The same analysis did not yield a main effect of group $\left(F_{(1,22)}=1.599\right.$, $p=0.219)$ nor of hemisphere $\left(F_{(1,22)}=0.006, p=0.937\right)$. Post hoc $t$ tests (one-tailed, Bonferroni corrected $p$ value $=0.025$ ) revealed increased connectivity values in the left $\left(t_{(22)}=2.636\right.$, $p=0.007$, Cohen's $d=1.193$ ) but not in the right hemisphere $\left(t_{(22)}=-0.729, p=0.237\right)$ in AP compared with NAP musicians (Fig. 3). We did not reveal within-group differences (Bonferroni corrected) in right- or left-hemispheric connectivity (AP $t_{(14)}=$ $1.816, p=0.045$; NAP $\left.t_{(8)}=-1.678, p=0.066\right)$. For reasons of completeness, we additionally evaluated connectivity in the following frequency bands: lower $\alpha(8-10 \mathrm{~Hz})$, upper $\alpha(10-12 \mathrm{~Hz})$, total $\alpha(8-12 \mathrm{~Hz})$, lower $\beta(13-16 \mathrm{~Hz})$, higher $\beta(17-20 \mathrm{~Hz})$, and total $\beta(13-20 \mathrm{~Hz})$. These analyses did not yield a main effect of group nor a group $\times$ hemisphere interaction effect, this result militating in favor of the specificity of $\theta$ oscillation in coordinating long-range circuits.

\section{Relationship between intracranial connectivity and pitch- labeling performance}

Based on previous work showing an influence of early music exposure (Gregersen et al., 2001; Deutsch et al., 2006) on AP 


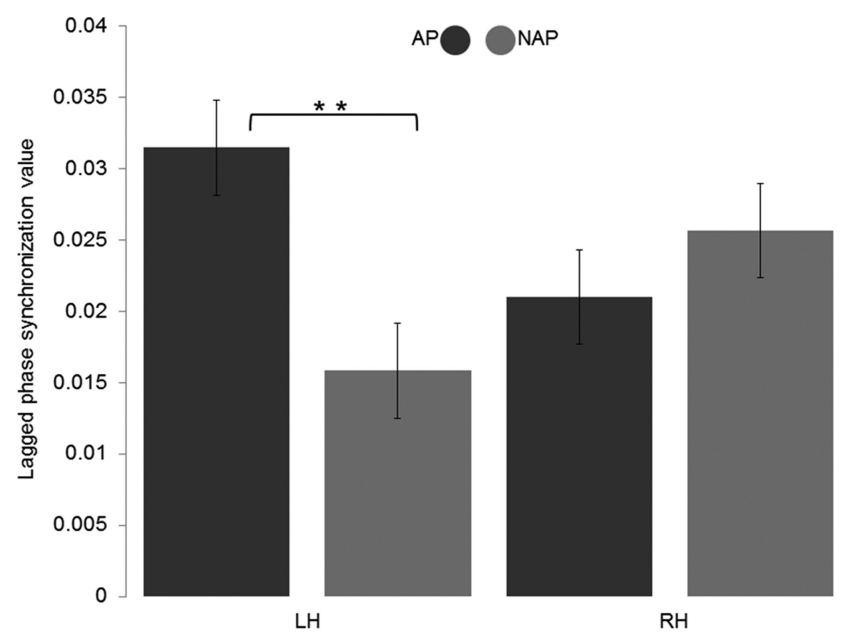

Figure 3. Intracranial connectivity. Lagged theta phase-synchronization values for the two groups and the two hemispheres. LH, left hemisphere; $R H$, right hemisphere. ${ }^{* *} p<0.01$. Error bars indicate SE.

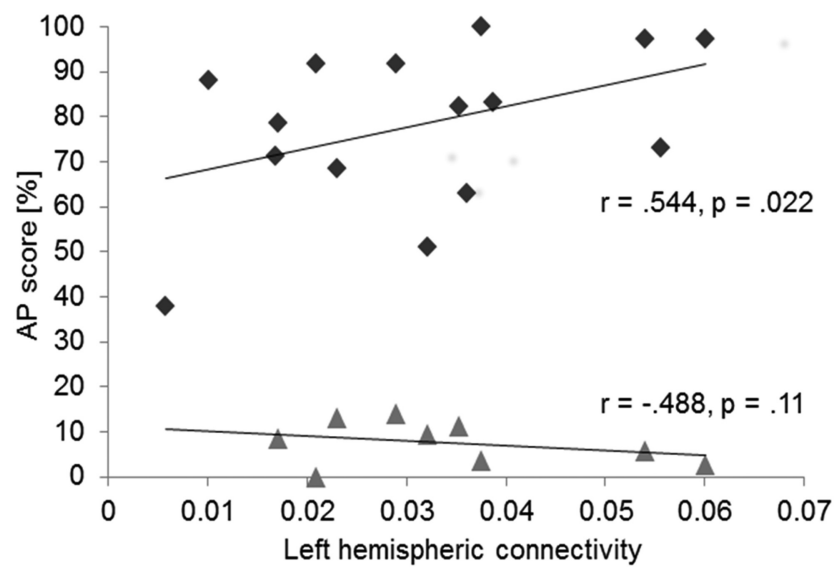

Figure 4. Correlative analyses. Partial correlations between AP performance and theta phase-synchronization values within the $\operatorname{AP}(N=15$; black diamonds) and $\operatorname{NAP}(N=9$; gray triangles) group.

ability, we computed within-group partial correlations (onetailed) between left-hemispheric connectivity and pitch-labeling performance by correcting for the influence of age of commencement of musical training. Within the AP group, functional connectivity was predictive of pitch-labeling performance $\left(\mathrm{AP} r_{p}=0.544\right.$, $p=0.022, r_{p}^{2}=0.295 ; \operatorname{NAPr}_{p}=-0.488, p=0.11$, one-tailed, Fig. 4).

\section{Discussion}

The main objective of the present work was to integrate two apparently opposite perspectives on AP, namely early "categorical perception" and "pitch labeling". Based on the assumption that a coexistence of these two theoretical frameworks can be explained by taking into account the functional interchange between sensory and cognitive brain regions, here we evaluated intracranial theta phase-coupling between the left ARC and DLPFC. Theta oscillations have previously been shown to reliably reflect mnemonic processes (Kahana et al., 1999; Caplan et al., 2001; Ward, 2003; Sauseng et al., 2005), information integration (Ward, 2003), and neuronal communication between distinct brain regions over long-range circuits (Ward, 2003; Polanía et al., 2012). The increased phase synchronization we revealed in AP musicians in a left-hemispheric network suggests that theta phase alignment between the ARC and the DLPFC may enable neuronal facilitation during pitch-label associations. Therefore, we propose that these "background" electrophysiological oscillations may constitute a salient marker that enables the objectification of the distinctive quality of AP. It is important to mention that our results are fully in line with a previous diffusion tensor imaging (DTI) study of Halwani et al. (2011) who compared fractional anisotropy and volume of the bilateral AF in a sample of musicians and non-musicians and provided evidence for AF symmetry in musicians regardless of the instrument trained.

Previous studies on AP have provided substantive support for functional-structural alterations of the left ARC (Schlaug et al., 1995; Hirata et al., 1999; Ohnishi et al., 2001; Luders et al., 2004; Schulze et al., 2009; Meyer et al., 2011; Matsuda et al., 2013) and DLPFC (Bermudez and Zatorre, 2005, 2009; for an alternative perspective consider Wengenroth et al., 2014). In addition, DTI data highlighted a relationship between AP ability and the architectural features of the left AF (Oechslin et al., 2009; Loui et al., 2011; Jäncke et al., 2012), a fiber bundle connecting the posterior supratemporal plane with prefrontal brain regions. Recently, Makris et al. (2005) reported that this specific fiber bundle is actually composed of four separate components, and that at least one specific subdivision is in earnest linked to the DLPFC. According to this evidence, data are interpreted as suggesting a relationship between the functional-anatomical organizations of left-hemispheric perisylvian territories and the temporal alignment of neuronal oscillations at rest. This perspective is compatible with recent methodological work showing a positive correlation between theta oscillations and white matter connectivity (Cohen, 2011) or an inverse relationship between cortical thickness and auditory-evoked potentials (Liem et al., 2012). According to underlying electrophysiological mechanisms, we propose that the opposite directions of the regression functions within the two groups may represent a functional change in the inhibitory-excitatory balance of perceptual-cognitive coupling mechanisms. Otherwise, it is even conceivable that theta phase alignment plays an indirect role in the modulation of crossfrequency nesting relations (Luo and Poeppel, 2007). Finally, based on previous work showing that structural hyperconnectivity between the left posterior superior temporal gyrus and the superior temporal sulcus might support "categorical perception" in AP subjects (Loui et al., 2011; Jäncke et al., 2012), it is even conceivable to assume that the left ARC may act as a hub of information flow toward prefrontal brain regions. Certainly, the specific physiological mechanisms underlying increased intracranial theta phase-coupling in AP musicians at rest have to be clarified in more detail.

In summary, based on our results and on the described discrepancy in the literature between perceptual and cognitive perspectives on AP, here we propose a novel integrative spatiotemporal model of AP. This model postulates that in AP subjects the tonal inputs and the corresponding mnemonic representations are tightly coupled in such a manner that this distinctive electrophysiological signature can still be detected during short resting-state periods. This is an important step toward a holistic and integrative understanding of the brain mechanisms supporting absolute-hearing behavior. Certainly, the influences of autobiographical and genetic features on this specific spatiotemporal coupling mechanism, and its relationships to functional and structural plasticity, have to be described in more detail. 


\section{References}

Annett M (1970) A classification of hand preference by association analysis. Brit J Psychol 61:303-321. CrossRef Medline

Baharloo S, Johnston PA, Service SK, Gitschier J, Freimer NB (1998) Absolute pitch: an approach for identification of genetic and nongenetic components. Am J Hum Genet 62:224-231. CrossRef Medline

Bermudez P, Zatorre RJ (2009) The absolute pitch mind continues to reveal itself. J Biol 8:75. CrossRef Medline

Bermudez P, Zatorre RJ (2005) Conditional associative memory for musical stimuli in nonmusicians: implications for absolute pitch. J Neurosci 25: 7718-7723. CrossRef Medline

Bermudez P, Lerch JP, Evans AC, Zatorre RJ (2009) Neuroanatomical correlates of musicianship as revealed by cortical thickness and voxel-based morphometry. Cereb Cortex 19:1583-1596. CrossRef Medline

Brett M, Johnsrude IS, Owen AM (2002) The problem of functional localization in the human brain. Nat Rev Neurosci 3:243-249. CrossRef Medline

Caplan JB, Madsen JR, Raghavachari S, Kahana MJ (2001) Distinct patterns of brain oscillations underlie two basic parameters of human maze learning. J Neurophysiol 86:368-380. Medline

Chen J, Dastjerdi M, Foster BL, LaRocque KF, Rauschecker AM, Parvizi J, Wagner AD (2013) Human hippocampal increases in low-frequency power during associative prediction violations. Neuropsychologia 51: 2344-2351. CrossRef Medline

Cohen MX (2011) Error-related medial frontal theta activity predicts cingulate-related structural connectivity. Neuroimage 55:1373-1383. CrossRef Medline

Crespo-Garcia M, Cantero JL, Atienza M (2012) Effects of semantic relatedness on age-related associative memory deficits: the role of theta oscillations. Neuroimage 61:1235-1248. CrossRef Medline

Deutsch D, Henthorn T, Marvin E, Xu H (2006) Absolute pitch among American and Chinese conservatory students: prevalence differences, and evidence for a speech-related critical period (L). J Acoust Soc Am 119: 719-722. CrossRef Medline

Deutsch D, Dooley K, Henthorn T, Head B (2009) Absolute pitch among students in an American music conservatory: association with tone language fluency. J Acoust Soc Am 125:2398-2403. CrossRef Medline

Elmer S, Meyer M, Jáncke L (2012) Neurofunctional and behavioral correlates of phonetic and temporal categorization in musically trained and untrained subjects. Cereb Cortex 22:650-658. CrossRef Medline

Elmer S, Sollberger S, Meyer M, Jäncke L (2013) An empirical reevaluation of absolute pitch: behavioral and electrophysiological measurements. J Cogn Neurosci 25:1736-1753. CrossRef Medline

Fuchs M, Kastner J, Wagner M, Hawes S, Ebersole JS (2002) A standardized boundary element method volume conductor model. Clin Neurophysiol 113:702-712. CrossRef Medline

Gordon EE (1989) Manual for the advanced measures of music education. Chicago: GIA.

Gregersen PK, Kowalsky E, Kohn N, Marvin EW (1999) Absolute pitch: prevalence, ethnic variation, and estimation of the genetic component. Am J Hum Genet 65:911-913. CrossRef Medline

Gregersen PK, Kowalsky E, Kohn N, Marvin EW (2001) Early childhood music education and predisposition to absolute pitch: teasing apart genes and environment. Am J Med Genet 98:280-282. CrossRef Medline

Halpern AR (1989) Memory for the absolute pitch of familiar songs. Mem Cognit 17:572-581. CrossRef Medline

Halwani GF, Loui P, Rüber T, Schlaug G (2011) Effects of practice and experience on the arcuate fasciculus: comparing singers, instrumentalists, and non-musicians. Front Psychol 2:156. CrossRef Medline

Hirata Y, Kuriki S, Pantev C (1999) Musicians with absolute pitch show distinct neural activities in the auditory cortex. Neuroreport 10:9991002. CrossRef Medline

Itoh K, Suwazono S, Arao H, Miyazaki K, Nakada T (2005) Electrophysiological correlates of absolute pitch and relative pitch. Cereb Cortex 15: 760-769. CrossRef Medline

Jäncke L, Langer N, Hänggi J (2012) Diminished whole-brain but enhanced peri-sylvian connectivity in absolute pitch musicians. J Cogn Neurosci 24:1447-14461. CrossRef Medline

Jung TP, Makeig S, Humphries C, Lee TW, McKeown MJ, Iragui V, Sejnowski TJ (2000) Removing electroencephalographic artifacts by blind source separation. Psychophysiology 37:163-178. CrossRef Medline

Kahana MJ, Sekuler R, Caplan JB, Kirschen M, Madsen JR (1999) Human theta oscillations exhibit task dependence during virtual maze navigation. Nature 399:781-784. CrossRef Medline

Kamiyama K, Katahira K, Abla D, Hori K, Okanoya K (2010) Music playing and memory trace: evidence from event-related potentials. Neurosci Res 67:334-340. CrossRef Medline

Keenan JP, Thangaraj V, Halpern AR, Schlaug G (2001) Absolute pitch and planum temporale. Neuroimage 14:1402-1408. CrossRef Medline

Lancaster JL, Woldorff MG, Parsons LM, Liotti M, Freitas CS, Rainey L, Kochunov PV, Nickerson D, Mikiten SA, Fox PT (2000) Automated Talairach Atlas labels for functional brain mapping. Hum Brain Mapp 10:120-131. CrossRef Medline

Lehrl S, Fischer B (1992) Kurztest für allgemeine Basisgrössen der Informationsverarbeitung (KAI). 3. Aufl. Vless. Ebersberg.

Levitin DJ (1994) Absolute memory for musical pitch-evidence from the production of learned melodies. Percept Psychophys 56:414-423. CrossRef Medline

Levitin DJ, Rogers SE (2005) Absolute pitch: perception, coding, and controversies. Trends Cogn Sci 9:26-33. CrossRef Medline

Liem F, Zaehle T, Burkhard A, Jäncke L, Meyer M (2012) Cortical thickness of supratemporal plane predicts auditory N1 amplitude. Neuroreport 23:1026-1030. CrossRef Medline

Loui P, Li HC, Hohmann A, Schlaug G (2011) Enhanced cortical connectivity in absolute pitch musicians: a model for local hyperconnectivity. J Cogn Neurosci 23:1015-1026. CrossRef Medline

Luders E, Gaser C, Jancke L, Schlaug G (2004) A voxel-based approach to gray matter asymmetries. Neuroimage 22:656-664. CrossRef Medline

Luo H, Poeppel D (2007) Phase patterns of neuronal responses reliably discriminate speech in human auditory cortex. Neuron 54:1001-1010. CrossRef Medline

Makris N, Kennedy DN, McInerney S, Sorensen AG, Wang R, Caviness VS Jr, Pandya DN (2005) Segmentation of subcomponents within the superior longitudinal fascicle in humans: a quantitative, in vivo, DT-MRI study. Cereb Cortex 15:854-869. CrossRef Medline

Matsuda A, Hara K, Watanabe S, Matsuura M, Ohta K, Matsushima E (2013) Pre-attentive auditory processing of non-scale pitch in absolute pitch possessors. Neurosci Lett 548:155-158. CrossRef Medline

Mazziotta J, Toga A, Evans A, Fox P, Lancaster J, Zilles K, Woods R, Paus T, Simpson G, Pike B, Holmes C, Collins L, Thompson P, MacDonald D, Iacoboni M, Schormann T, Amunts K, Palomero-Gallagher N, Geyer S, Parsons L, et al. (2001) A probabilistic atlas and reference system for the human brain: International Consortium for Brain Mapping (ICBM). Philos Trans R Soc Lond B Biol Sci 356:1293-1322. CrossRef Medline

Meyer M, Elmer S, Ringli M, Oechslin MS, Baumann S, Jancke L (2011) Long-term exposure to music enhances the sensitivity of the auditory system in children. Eur J Neurosci 34:755-765. CrossRef Medline

Nolte G, Bai O, Wheaton L, Mari Z, Vorbach S, Hallett M (2004) Identifying true brain interaction from EEG data using the imaginary part of coherency. Clin Neurophysiol 115:2292-2307. CrossRef Medline

Oechslin MS, Imfeld A, Loenneker T, Meyer M, Jäncke L (2009) The plasticity of the superior longitudinal fasciculus as a function of musical expertise: a diffusion tensor imaging study. Front Hum Neurosci 3:76. CrossRef Medline

Oechslin MS, Meyer M, Jäncke L (2010) Absolute pitch-functional evidence of speech-relevant auditory acuity. Cereb Cortex 20:447-455. CrossRef Medline

Ohnishi T, Matsuda H, Asada T, Aruga M, Hirakata M, Nishikawa M, Katoh A, Imabayashi E (2001) Functional anatomy of musical perception in musicians. Cereb Cortex 11:754-760. CrossRef Medline

Pascual-Marqui RD, Lehmann D, Koukkou M, Kochi K, Anderer P, Saletu B, Tanaka H, Hirata K, John ER, Prichep L, Biscay-Lirio R, Kinoshita T (2011) Assessing interactions in the brain with exact low-resolution electromagnetic tomography. Philos Trans A Math Phys Eng Sci 369:37683784. CrossRef Medline

Polanía R, Nitsche MA, Korman C, Batsikadze G, Paulus W (2012) The importance of timing in segregated theta phase-coupling for cognitive performance. Curr Biol 22:1314-1318. CrossRef Medline

Rogenmoser L, Elmer S, Jäncke L (2014) Absolute pitch: evidence for early cognitive facilitation during passive listening as revealed by reduced $\mathrm{P} 3 \mathrm{a}$ amplitudes. J Cogn Neurosci 29:1-15. CrossRef Medline

Sauseng P, Klimesch W, Schabus M, Doppelmayr M (2005) Fronto-parietal EEG coherence in theta and upper alpha reflect central executive func- 
tions of working memory. Int J Psychophysiol 57:97-103. CrossRef Medline

Schlaug G, Jäncke L, Huang YX, Steinmetz H (1995) In-vivo evidence of structural brain asymmetry in musicians. Science 267:699-701. CrossRef Medline

Schulze K, Gaab N, Schlaug G (2009) Perceiving pitch absolutely: comparing absolute and relative pitch possessors in a pitch memory task. BMC Neurosci 10:106. CrossRef Medline

Siegel JA (1974) Sensory and verbal coding strategies in subjects with absolute pitch. J Exp Psychol 103:37-44. Medline

Stam CJ, van Straaten EC (2012) Go with the flow: use of a directed phase lag index (dPLI) to characterize patterns of phase relations in a large-scale model of brain dynamics. Neuroimage 62:1415-1428. CrossRef Medline

Takeuchi AH, Hulse SH (1993) Absolute pitch. Psychol Bull 113:345-361. CrossRef Medline

Ward LM (2003) Synchronous neural oscillations and cognitive processes. Trends Cogn Sci 7:553-559. CrossRef Medline
Wengenroth M, Blatow M, Heinecke A, Reinhardt J, Stippich C, Hofmann E, Schneider P (2014) Increased volume and function of right auditory cortex as a marker for absolute pitch. Cereb Cortex 24:1127-1137. CrossRef Medline

Wu C, Kirk IJ, Hamm JP, Lim VK (2008) The neural networks involved in pitch labeling of absolute pitch musicians. Neuroreport 19:851-854. CrossRef Medline

Zatorre RJ (2003) Absolute pitch: a model for understanding the influence of genes and development on neural and cognitive function. Nat Neurosci 6:692-695. CrossRef Medline

Zatorre RJ, Beckett C (1989) Multiple coding strategies in the retention of musical tones by possessors of absolute pitch. Mem Cognit 17:582-589. CrossRef Medline

Zatorre RJ, Perry DW, Beckett CA, Westbury CF, Evans AC (1998) Functional anatomy of musical processing in listeners with absolute pitch and relative pitch. Proc Natl Acad Sci U S A 95:3172-3177. CrossRef Medline 